\title{
To vaccinate or not to vaccinate: how teenagers justified their decision
}

\section{Mats Lundström, Margareta Ekborg \& Malin Ideland}

\section{Cultural Studies of Science Education}

ISSN 1871-1502

Cult Stud of Sci Educ

DOI 10.1007/s11422-012-9384-4

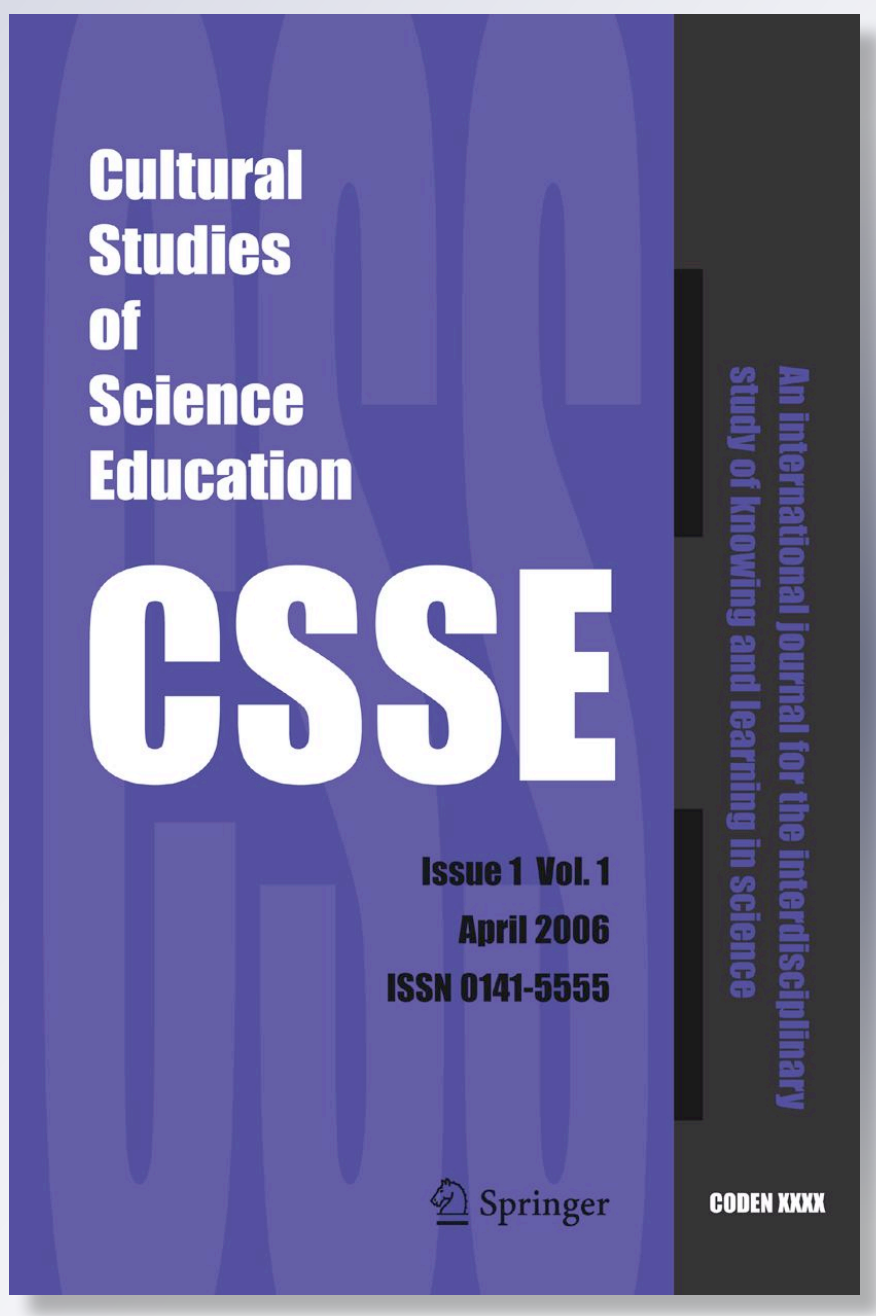

望 Springer 
Your article is protected by copyright and all rights are held exclusively by Springer Science+Business Media B.V.. This e-offprint is for personal use only and shall not be selfarchived in electronic repositories. If you wish to self-archive your work, please use the accepted author's version for posting to your own website or your institution's repository. You may further deposit the accepted author's version on a funder's repository at a funder's request, provided it is not made publicly available until 12 months after publication. 


\title{
To vaccinate or not to vaccinate: how teenagers justified their decision
}

\author{
Mats Lundström • Margareta Ekborg • Malin Ideland
}

Received: 30 March 2011 / Accepted: 2 January 2012

(C) Springer Science+Business Media B.V. 2012

\begin{abstract}
This article reports on a study of how teenagers made their decision on whether or not to vaccinate themselves against the new influenza. Its purpose was to identify connections between how teenagers talk about themselves and the decision they made. How do the teenagers construct their identities while talking about a specific socio-scientific issue? Seven teenagers between 17 and 19 years of age participated in the study. The informants were requested to document in video diary situations in which their decisions about the vaccination were discussed. All the teenagers recorded their diaries during the weeks of the vaccination programme. The students were also interviewed 1-4 weeks after completing their diaries. A discourse psychology framework (Potter and Wetherell 1987) was used to analyse the video diaries and the interviews. In this context, decision-making on a socioscientific issue must be understood as an appropriation and use of discursive repertoires, and also as meaning-making in relation to other fields, such as society and identity. It must also be understood in relation to the use of science repertoire-or actually, the school science repertoire-how available is this discourse in different contexts outside school? The repertoires were categorised into two main types; experienced emphases and important actors. The first included the categories of risk, solidarity and knowledge. The second included family and friends, media, school and society. The school repertoire was seldom used by the students, indicating that school and science education seem not to be an interpretative repertoire available to them. Instead, the risk, solidarity, family and friends and the media repertoires were available in their talk about vaccination. These results indicate the need to use media reports in dealing with scientific literacy and also in risk assessment discussions in school. It also indicates the importance of relating school science closely to the students' daily life.
\end{abstract}

Keywords New influenza · Vaccination · Decision-making · Video diary · Discourse psychology

M. Lundström ( $\square) \cdot$ M. Ekborg · M. Ideland

Malmö University, Malmö, Sweden

e-mail: mats.lundstrom@mah.se 
In 2009 and 2010, an influenza pandemic, "swine flu," was given a great deal of media attention in many countries. Swine flu is a disease whose proper name is actually "the new influenza" and it is caused by a virus-A(H1N1). It is spread through airborne drops of liquid, for instance by sneezing or in saliva. In February 2009, the first reported cases came from Mexico and North America and shortly after that, newspapers, television, radio and various social media discussed the disease and how it influenced peoples' health. In Sweden the first reported case occurred in May 2009. For several months, the new influenza was headline news both in newspapers and on television news broadcasts. Different aspects of the pandemic were discussed in the media, but the main theme was the government's advice to the public to inoculate against the influenza. The Swedish government took the decision to distribute and offer free vaccination to all citizens. Despite the offer of free vaccination, not everyone chose to be vaccinated. However, more than $60 \%$ of the Swedish population was inoculated against the influenza up to May 2010, by which time 29 Swedes were reported to have died from the illness. During the rest of 2010, fewer cases of infections or deaths were reported, but different kinds of side effects caused by the vaccination were also described, for instance narcolepsy (Swedish Institute for Infectious Disease Control 2010). These reported side effects opened up a discussion in the media about the positive and negative effects of the vaccination. The new influenza and its associated vaccination gave birth not only to well-articulated reports and articles but also to a great deal of speculation and rumour. One of the examples is a clip from You Tube (2010) where an American news station reports about a girl who only could walk backwards, explaining this phenomenon as a side effect of an influenza vaccination.

The break out of a pandemic could be an interesting case study for biology education. It is an example of applied immunology and how knowledge and research in biology is used in society. But it is also an opportunity for research in science education to investigate in what ways people interpret scientific and other information and make decisions about their health. In recent decades it has been emphasized that science education must contribute to the public understanding of science or scientific literacy and by that facilitate an individual's decision-making (see Roberts 2007). By knowing more about the decision-making of individuals and how they justify their choices, it might be easier for science education to capture the interest of students and to promote decision-making where scientific knowledge may play a role. The vaccination was offered to the whole Swedish population but it was up to the individual or in the case of minors their parents, to make the decision. In this way the message from the government was obvious; as many people as possible should be vaccinated to prevent a pandemic. This situation is an example of what Ulrich Beck (1999) calls the risk society, where individuals have to make decisions about how to handle a health problem. An inoculation gives protection against the disease but might cause side effects. This is also the case with other vaccinations, but the new influenza and the vaccination against it was given sharper focus in public debate at this time compared to what commonly is given to vaccination against measles or polio, even if there are some similarities in campaigns for vaccination. Information was divergent and sometimes contradictory because, for instance, of the richness of different sources on the internet. Nowadays, the media landscape gives plenty of opportunities of obtaining information. This fact raises questions about how people handle information and what impacts their decisions. In what way is a decision about an up-coming health issue made? What questions are of importance when an individual justifies the decision to have the vaccination or not, and in what ways does science education contribute to the decision? 
This article reports from a study in which students in upper secondary school have documented what influenced their choice about the vaccination. They have already made their decision about the vaccination. The aim of the study is to analyse how students in upper secondary school justify their decision about the new influenza vaccination and how they at the same time talk about themselves and who they want to be. The students have mainly used video diaries to document their reasoning about the swine flu and its risks. They have also been interviewed about their decision about the vaccination and to what extent the school has paid attention to the pandemic. In order to analyse the data from a perspective where the student's justification for his or her decision is of interest, discourse psychology (Potter and Wetherell 1987) has been used as an analytical tool. In discourse psychology, the focus is on how individuals use language to construct versions of the world and of their "selves"; constructing an understandable world.

\section{The risk society and students' decision-making about risks}

Beck (1992) discusses the contemporary society from a risk perspective. Beck states that civilization today has to face a lot of different types of risk. He defines risk as a "systematic way of dealing with hazards and insecurities induced and introduced by modernization itself" (Beck 1992, p. 21.) Beck in this way distinguishes between risks and dangers. He considers the judgment of risks as difficult but necessary for the individual. In the judgment, both for the individual and for society, different types of experts are central. Knowledge from natural sciences and human sciences are used and rationality, fact and interest are involved in the process of risk determination. Anthony Giddens (1991) also asserts that risk assessment is of great importance for the individual but emphasizes its associated difficulties, because there are always unintended and unforeseen outcomes. According to Beck it is often science that has both caused the problem and provided the solution. Beck argues that the risk society is in a sense a science, media and information society. In that way risk is something for the individual to handle and decide about in his or her daily life. Giddens (1991) mentions that notions of risk and trust have particular importance in decision-making in late modern society. Giddens also talks about fateful moments, "when individuals are called on to take decisions that are particularly consequential for their ambitions, or more generally for their future life" (Giddens 1991, p. 112). These fateful moments are not activities in day-to-day life but instead moments where the decision is felt to be very important for the individual, such as, for example, the risks of a possible deadly disease like the new influenza. These fateful moments are influenced by, and may influence, the individual's sense of ontological security, including how the individual understands the risks connected to the moment. Aaron Wildavsky and Karl Dake (1990) discuss the different theories about what determines how an individual regards risks. They demonstrate how cultural biases are more decisive in risk perception compared to other suggested explanations such as knowledge, personality, personal economy or political opinion. In cultural biases they include factors such as views about egalitarianism, individualism and hierarchies. By contrast, Maria Powell et al. (2007) instead found that emotions (worry and anger) are strongly associated with the perceived likelihood of becoming ill. Both Wildavsky and Dake (1990), and Powell et al. (2007) emphasize the complexity and difficulties in analysing risk behaviour.

Stein Kolstø (2006) considers that making a decision in a risk situation is often about how to judge a disputed scientific claim. Kolst $\varnothing$ thinks that there is almost always some science related to the question even if it sometimes is not obvious. Clare Christensen (2009) argues that the role of risk understanding and risk judgment not has been addressed 
sufficiently in different studies of socio-scientific issues. However, there are some studies that have investigated socio-scientific issues and risks. Kolst $\varnothing$ (2006) investigated students' decision-making arguments about a local power transmission line-whether it should be buried in the ground because of the possible risk of increasing childhood leukaemia if the line is in the air. After group discussions and interviews Kolst $\varnothing$ categorised the students' reasoning patterns in to five categories. In the first category, students thought that the risk was too small to justify the high costs from underground lines. Kolst $\varnothing$ calls this category the "relative risk." The second category is the "precautionary argument"; students emphasize "safety first" even if the risk is small. There were also students in the study who could not come to a decision about what to do. In the fourth category were those students who considered that risks are a natural part of our life and not a big issue. Kolstø (2006) placed students who truly weighed the advantages and disadvantages before they made their decision in the fifth category. To certain extent, these advantages and disadvantages may be grounded in the individual's view of science. In an earlier study, Kolstø (2001) demonstrated different "resolution strategies" when upper secondary students were interviewed about the power transmission lines. The different strategies were to evaluate, or accept in combination with the statement that was made, or to refer to authorities. The students did not consider the content; it was more common to evaluate the sources. In this way, authority is often treated as a surety of validity and reliability.

The importance of authority in risk assessment is demonstrated in several studies. For example, Margareta Ekborg (2008) also demonstrates that authorities are important, such as when students think it is difficult to consider risks. In her study upper secondary students in the science programme discussed GMO (genetically modified organisms). Ekborg found that risk was an important factor when making a decision about GMOs. When the students in the study were unable to judge the risk of the use of GMOs they instead evaluated the reliability of the researchers of GMO. There was no correlation in Ekborg's study between knowledge about what GMO is, and opinion about it.

In the debate on the new influenza, many different types of authorities tried to make their voice heard, but the rich quantity of sources may have made it hard to take notice of all of them, and even harder to evaluate. There were many different messages about the risks of the disease and the vaccination that was offered.

\section{Risk and vaccinations}

Sandra Duggan and Richard Gott (2002) interviewed parents at a local child care centre on their view of vaccinations and personal decision-making about immunization. Duggan and Gott categorised the parents' answers into four "concepts of evidence" that were important in making the decision to vaccinate their children or not: risk, incidence of disease, efficiency of vaccine in preventing disease and validity of reports about risk. The precautionary principle is often emphasized. Mike Poltorak et al. (2005) found how important different personal histories are in determining the willingness to vaccinate one's children against MMR (mumps, measles, and rubella). These histories include parenthood experiences, knowledge, ways of validating and engaging with information and expectations of health professionals. In this way, when parents talk about MMR, they do not merely expose their scientific reading, but also their responsibility for the child, their trust in institutions and how they place themselves amongst their friends. Malin Ideland (2007) has made a study of Swedish parents' decision-making concerning MMR. This study also shows that parents justify their decision to vaccinate their children or not by using personal 
experience. Relationship to families with an autistic child is highlighted in several interviews and is described as a motive not to vaccinate. On the other hand, parents who chose to vaccinate sometimes legitimate this decision with close relationships to persons who really could be affected by diseases like rubella or measles. Even if the mass media had put the issue of MMR vaccine and autism on the agenda, it was personal experience that was used in justifying decisions. According to Duggan and Gott (2002), interest in an issue like immunization often starts in social concern about government intention behind a vaccination campaign. Suspicion and mistrust may lead to the start of action groups. This mistrust may be seen in a larger context as apprehension to science. Beck (1992) stresses that there is a strong difference between how individuals evaluate and think about side effects. While scientists only trust scientific proof, a lay person sees it in another wayperhaps when a child falls ill shortly after a new occurrence in the neighbourhood. Ellen Peters et al. (2007) agree that patients and consumers in some cases have difficulties with, for example, the likelihood of side effects. However, Peters et al. emphasize that health information has been demonstrated to make individuals understand risks differently and thus strengthens the health literacy among patients and consumers.

\section{Media reports about influenza and science}

This was not the first time a vaccine was discussed in a lively media debate. When the smallpox vaccine was introduced in the late 18th century there were many rumours about what could happen if you were inoculated with cowpox-a virus similar to the smallpox virus. In the late 20th century a criticized-and later withdrawn-scientific report on connections between MMR vaccine and autism caused concern and also a decrease in how many children were vaccinated all over the western world (Ideland 2007). The media "vaccine-genre" is, in other words, something recurrent; the fear of side effects is discussed in relation to the fear of the disease. In the latest case, the risk of getting narcolepsy has been discussed.

One aggravating aspect in understanding media reports is, according to Connie Korpan et al. (1997), that they are often brief and preliminary and sometimes contradictory, which make them hard to understand. This was the case with reports about the new influenza during the autumn of 2009. On the one hand, the influenza was reported to be a disease that could lead to death, while on the other hand there were reports that the vaccination against it could in some cases lead to unpleasant side effects. The different side effects were reported in different media, not only national broadcasting and newspapers, but also Facebook-groups and other websites where all users have the opportunity to comment. Kevin Burchell et al. (2009) talk about a shift characterised as moving from deficit to dialogue, from "top-down" communication to "two-way" dialogue, where a lot of actors participate in the media debate.

Despite these new media channels, the debate on the new influenza followed-as described above-an established genre for how to report on scientific and technological risks. Sheldon Ungar (2008) examined different media reports from the "bird influenza" outbreak from April 2004 to March 2006 and came to the conclusion that the reports follow the same pattern. Ungar identified three stages of discourse. In the first, fear-inducing claims dominate, sounding the alarm-something also reported by Birgitte Nerlich and Christopher Halliday (2007) as the "rhetoric of fear" in media messages about the avian influenza. In the second, the mixed message discourse, the threats are more moderate and include scientific messages and national plans against the influenza. The last, called hot 
crisis and containment, involves effort to ameliorate the most frightening elements of the disease and the spread of the virus.

The capacity to follow and evaluate discussions about science in the media is often emphasized and reported as a deficit in the scientific literacy among students (Jarman and McClune 2010). These authors bring forward the necessity of being able to interpret and handle media information. Stephen Norris et al. (2003) reports about deficiencies in the capacity of university students to interpret and make appropriate judgments about media reports that describe scientific research. The students in the study also had an inflated view of their capacity to evaluate the five given media reports.

Since there are specific genres for media reporting on scientific issues in general-and vaccination in particular-the reporting naturally sheds light on some perspectives and hide others. One example is that science reporting often is not able to describe the whole research process including, for example, the review process (León 2008). This review process is important to valid research results but may vary in time depending on the issue. In the case of the new influenza, the review process was to some degree going on continuously through the vaccination period because of the short time between the break-out of the pandemic and the call for an effective vaccine. In this way the media consumer becomes a part of the evaluation of the vaccine, the media consumer has a responsibility to make the "right" decision for him-/herself and society. Responsibility for your own decisions is an important part of the "risk society" (Giddens 1991) and many studies emphasize the importance of training students' competence in decision-making without complete information (Christensen 2009).

Russell Tytler et al. (2001) summarise the interaction between science and the public as a negotiation of different perspectives, both knowledge and values, where judgments about evidence are of great concern. This diverging image of how individuals think about and deal with science have been discussed for several years (Irwin and Wynne 1996). It is to some degree dependent on the individual's ability to handle science knowledge, to be scientifically literate. Science is a complex field of knowledge and not easy to handle. Brian Wynne (1991) states that not even among scientists themselves is there any consensus about what science or scientific knowledge is. According to Wynne are the opinions about what science is differs, and is sometimes even contradictory among science experts.

\section{Science education and daily life}

The ability to use knowledge in science as an active citizen has been emphasized by both researchers (e.g., van Eijck and Roth 2010) and organisations like OECD (2007). Normally this knowledge is expressed as scientific literacy (SL) and describes "the capacity to use scientific knowledge, to identify questions and to draw evidence-based conclusions in order to understand and help make decisions about the natural world and the changes made to it through human activity" (OECD 2003, p. 133). The phrase about understanding and help in making decisions indicates that scientific literacy is not only a matter of handling different concepts, but also being able to include in scientific knowledge as one important factor, as well as, for example, economical or social factors, when making a decision. Korpan et al. (1997) emphasize that individuals must comprehend, interpret, and evaluate information and conclusions based on scientific research to be scientific literate. Wynne (1991) states that the capacity of the public to absorb science is not a matter of intellectual capability, but rather is dependent on whether it seems useful and in line with public or personal experience. Jonathan Osborne and Justin Dillon (2008) consider that science 
education today must educate students to be critical consumers of scientific knowledge. They also criticise school science for being so distant from the science reported in the media. The new influenza and the vaccination are seen here as one example where students and their parents must be critical consumers of information. The dilemma of the vaccination can be regarded as a socio-scientific issue, where the use of scientific knowledge is one way of dealing with the issue. This study does not directly investigate scientific literacy in a traditional way, but instead analyses if the students include any scientific knowledge when they justify their decisions about the new influenza and the vaccination against it, thereby meeting the demands reported above about an active citizen using scientific knowledge (Roberts 2007). This way of analysing the use of scientific literacy in an out of school-context also meets the demands from Michiel van Eijck and WolffMichael Roth (2010) who call for research about scientific literacy "in the wild." By "in the wild' they just mean in an everyday context, outside school.

Another way to look at science connections to everyday life is to talk about its role in students' identity construction. This takes its departure from a social theory on learning (Lave and Wenger 1991). The primary focus of this theory is that you learn when you participate in social practices and communities and when you are able to construct an identity in relation to these. Learning and identity building are in other words interdependent on each other; "meaning is constructed in relation to the community, specific practice and the identity" (Wenger 2008, p. 5). Several researchers have emphasized the importance of increasing the knowledge on connections between students' identities and their interest and learning in science. Nancy Brickhouse states that:

In other words, in order to understand learning in science, we need to know much more than whether students have acquired particular scientific understandings. We need to know how students engage in science and how this is related to who they are and who they want to be (Brickhouse 2001, p. 286).

Troy Sadler (2009) also emphasizes the importance of students attaining the ability to learn science in a community where they can be central participants and express their identities. In an education departing from science culture and scientific work forms, students have few chances to participate and express their identities. But, according to Sadler (2009), if the teaching is framed by issues important to the students themselves, they become more central participants and the chance to make meaning, express their identities and learn increase.

Etienne Wenger (2008) highlights shared discourses as one aspect of a community. Sadler (2009) emphasizes the importance of being able to understand the cultural codes and use the discourses inside a community. Jay Lemke has also brought forward this aspect:

In the sociocultural view, what matters to learning and doing science is primarily the socially learned cultural traditions of what kinds of discourses and representations are useful and how to use them, far more than whatever brain mechanisms may be active while we are doing so (Lemke 2001, p. 298).

In this view, science learning must be understood not only as an appropriation and use of discourses, but also as meaning-making in relation to other fields, to society and to identity. It must also be understood in relation to what happens with the use of science discourse - or actually the school science discourse-when it is expected to be available outside school in different contexts; something this article deals with. Glen Aikenhead (2006) and Jim Ryder (2001) emphasize the difficulties of using canonical science outside 
school. Aikenhead describes this as a transformation where the content must be deconstructed and then constructed according the idiosyncratic demands of the context. Decision-making about the new influenza vaccination is one example where this transformation of content seems relevant.

\section{Vaccination as a socio-scientific issue}

All various information about the new influenza would lead to a decision about having the vaccination or not. The decision about the vaccination can in science education be regarded as a socio-scientific issue (SSI). Mary Ratcliffe and Marcus Grace (2003) describe a socioscientific issue "to be one which has basis in science and has a potentially large impact on society" (2003, p. 1). Socio-scientific issues have attracted attention in science education in recent years and proposed as an appropriate means to discuss and learn about the connections between science and society (Sadler 2009). The vaccination question has its origin in science, in knowledge about immunology and how to handle pandemics. Already included in the classification of a disease as a pandemic is a definition of potentially large impact on society thus meeting Ratcliffe and Grace's (2003) definition of SSI. Ratcliffe and Grace (2003) mean that decisions are not only based on scientific facts, but also argue for the influence of our priorities, values, beliefs and role in society when deciding and eventually take action on a personal level. They demonstrate in a study about socioscientific issues that increased exposure to different media reports combined with structured questions improve reasoning skills among students that initially operate at a low level in this sort of reasoning. This study investigates if the students include any scientific knowledge when they justify their decisions about the vaccination and what information or information sources they find trustworthy.

\section{Trustworthiness}

One key concept in the reasoning about scientific literacy, socio-scientific issues and how individuals handle evidence is trustworthiness. Kolst $\varnothing$ (2001) has investigated what adolescents dealing with socio-scientific issues count as trustworthy and how they make personal decisions concerning what actions to make. Kolstø denotes the concept trustworthiness as the extent to which information and knowledge claims are seen as sufficiently reliable or not to be included in the pupils' knowledge-base for decision-making. Decision-making is to a high degree grounded in trust in different sources. Disagreement among researchers in science is for many students frustrating even if this is common in research in science (Christensen 2009). Christensen (2009) and Ratcliffe and Grace (2003) think this frustration may be due to the fact that science knowledge presented in school is often ready-made and presented as consensus. The process about how consensus is reached in the science community is according to Kolst $\varnothing$, an important epistemological question which is not always addressed in science education.

Kolst $\varnothing$ (2006) demonstrates the importance of authorities even if the students considered information from those others than experts. Kolst $\varnothing$ (2001) defines authorities as sources of knowledge, because the pupils in his study often seemed to look not at the content of the knowledge claims but instead at the sources of the claims. In his study about adolescents' reasoning on power transmission lines and the fear that the lines 
might cause childhood leukaemia, authorities played an important role in the students' reasoning about trustworthiness. Mats Lundström and Anders Jakobsson (submitted) also demonstrate the importance of authorities when reasoning about health issues. In that study students in upper secondary school discussed different web site answers to questions related to health. The students often referred to authorities as researchers or the pharmacy when deciding which answer was most trustworthy. In a study by Shu-Nu Chang and Mei-Hung Chiu (2008), science major students at undergraduate level performed better in informal argumentation in different SSIs (for example about GMO, dioxins, and DDT and malaria) compared to non-science majors. The science majors use authorities in their reasoning to a lower degree than other students, indicating that authorities are less important if you have or at least think you have knowledge of the subject.

In this study, the authority-concept is replaced by actor. This is chosen because the entity that normally is included in the concept of authority was not easy to evaluate in this case. An authority is mostly associated with some kind of knowledge. Often there is agreement between the concepts, but not always. The actor-concept demonstrates that there is something that can be related to in the issue, but does not value the source as highly as the authority-concept does.

\section{Purpose and research question}

The purpose of this study is to develop knowledge about connections between how students in upper secondary school talk about themselves and the decision they made about the new influenza and the vaccination against it. The purpose is also to investigate if the students cite school and science education as an available repertoire of a discourse on the new influenza.

- How are the decisions about the vaccination justified among upper secondary students?

- How can this decision-making be understood in relation to the students' discursive constructions of themselves in a specific social context?

\section{Methodology}

Research on students' scientific literacy and decision-making is often made in a school context. Different types of methods, like interviews or group discussions are normally connected to the daily activity in school or to some activity performed by the researcher. Kolstø (2006) considers that empirical research on rational reasoning has been experimental and based on tasks with structured problems. Often, the shortage of reasoning carried out by people has been in focus. However, not only rational reasoning has been considered. Troy Sadler and Dana Zeidler (2005) identified three patterns characterising student decision-making: rationalistic, emotive, and intuitive informal reasoning. Despite this widening of the argumentation research, there has been criticism against this way of investigating reasoning because it differs from real-world decisions (Shafir et al. 1993) and decision-making in daily life (Kolstø 2006). Even if the examples in studies made in school are real, there is a risk that the students regard the tasks as unimportant and as inauthentic decisions or decisions not concerning them. 
With that criticism in mind, the aim of this study was to leave the school context to a certain degree and instead focus on young peoples' daily life and the process of decisionmaking in a current SSI. It is therefore also an attempt to meet the demands of Christensen (2009) about more research about risk assessment by individuals and from van Eijck and Roth (2010) about investigating scientific literacy "in the wild." In this way, the ambition was to come closer to the informants' life outside school. These ambitions led to the decision to use video diaries as a tool to collect data and in that way study decision-making in a context outside school, in a situation where making a decision affects life. The video diary is a form of visual ethnography (Pink 2001) where the informant gets instructions, but chooses for him or herself what, where and when documenting is carried out. Andrew Noyes (2004) and Debby Cotton et al. (2010) assert that data from video diaries provide a fuller representation or description of social life. The challenge of recording, analysis and interpretation is magnified. The data is arguably richer than conventional interview transcripts. It can be discussed how "in the wild" any type of observation study is, even this one. The presence of a video camera affects the informant's behavior (Pink 2001) and the task was given by a researcher. However, an out of school context is regarded as more "in the wild" compared to the classroom. Thus a video diary study was regarded as an appropriate way of investigate everyday life. The video diary data collection was combined with interviews. Ruth Holliday (2004) suggests that video diaries are mainly a one-way conversation. She recommends follow-up interviews to achieve two-way conversation about the issues discussed in the video diaries. Dorte Buchwald et al. (2009) and Nuzhat Quadri and Peter Bullen (2007) also suggest that an interview after the making of a video diary gives the researcher the opportunity to understand more about the information given by the informants.

The purpose of this study is not just to analyse the content in the argumentation as is the case in many studies of decision-making. Neither is it to analyse argument from Stephen Toulmin's (2003) reasoning pattern: something that also is common in science education studies. Instead, the aim is to meet the criticism from Christensen (2009), Kolstø (2006) and Shafir et al. (1993) discussed above. Students' justification or legitimisation of the decision they make are in focus. To be able to reach this goal, a framework that focuses on the meaning-making of the individual is used. Using discourse psychology as an analytical tool for the way students construct their world, the justifications of decisions appropriate for themselves is analysed. The use of discourse psychology in science education research has been proposed by Wolff-Michael Roth (2008). In studies of scientific literacy students are often categorised in subgroups and in that way seen as individuals with enduring, stable opinions or values (for example, see Kolstø 2006). In this study, students' opinions and values are seen instead as context-dependent and not necessarily as enduring and stable (Potter and Wetherell 1987).

\section{Discourse psychology}

Potter and Wetherell (1987) include all forms of spoken interaction in discourse, formal and informal, and written texts of all kind. Discourse can be explained as a certain way of talking about and understanding the world (or a part of the world). This approach emphasizes that the way we understand the world is historically and culturally dependent and thereby contingent (Winther Jørgensen and Phillips 2000). In line with ethno methodology discourse analysis has its focus on how people use their language to do things (Potter and Wetherell 1987). "People are using their language to construct versions of the social world. This construction implies active selection where some resources are included 
and some omitted" (Potter and Wetherell 1987, pp. 33-34). The language is both constructing and constructed and the aim is to investigate how people themselves manage, understand and use descriptions. By analysing texts from the students in the study, an opportunity to understand how the informants construct their "new influenza world discourse" is possible. Their uses of language construct justification for their knowledge and decision-making. The new influenza vaccination decision was to a large extent a matter of handling, understanding and managing all diverging information. These circumstances make a discourse analysis proper as an analytical tool for decision-making.

Discourse psychology is based on the social constructivist assumption that the $\mathrm{I}$ is not an isolated autonomic agent, but is instead social and arises, transforms and is an object for negotiations in social practice (Winther Jørgensen and Phillips 2000). Discourse psychology rejects the idea that individuals have a solid identity. When you talk you also construct an identity and individuals have several flexible identities. Different discursive resources are used in different social relations. However, one does not assume a new identity every time one talks; strata of earlier discursive practices are important in expressed identity (Wetherell and Potter 1992). Norman Fairclough (1992) emphasizes that texts are full of snatches from other texts. The new text assimilates, contradicts, and so forth, other texts. New texts stress the historicity of texts and are reproduced even if the new text transforms. Sometimes this inter-textuality is manifested when specific other texts are obviously drawn in. In discourse psychology, the rhetorical organisation is in focus: how text and talk are oriented towards social action.

Often, the concept "interpretative repertoire" is used instead of discourse to emphasize the discursive resources' flexibility in social action. Evaluating action in terms of interpretative repertoires is an alternative way of comparing how attitudes, beliefs and attributes are described as mental constructions which are stable and hard to change (Potter and Wetherell 1987). "Interpretative repertoires are recurrently used systems of terms used for characterizing and evaluating actions, events and other phenomena" (Potter and Wetherell 1987, p. 149). The interpretative repertoire will be organized around specific metaphors and figures of speech. In this way, a repertoire is not connected to a certain social group and an individual may use different interpretative repertoires in different situations or contexts. Evaluating action will be of great importance when the aim is to analyse how decisions about the influenza and associated vaccination are justified. In our analysis, we can only analyse how the students construct a, for them understandable, world view about the new influenza at just that moment, not their attitude to it for a long period of time. In the analysis, we are also interested in how the informants justify their decisions at the same time as they talk about their "selves," how they want to be perceived and how this role also strengthens their arguments.

\section{Data collection}

An email with a missive about the research project was sent to 20 upper secondary schools, asking for students that were interested in making video-diaries of their daily life and in what ways they think science education plays a part of their daily life. The different schools were asked to distribute the message further to the students at their school. After that, it was up to the students to answer our call. We also talked about the project in some classes where the teacher wanted us to do so. Finally, seven students were identified as interested in participating in the project. This way of asking for student volunteers entails 
questions about representation. Students who want to be heard and enjoy filming themselves may participate to a higher degree than shy students. The aim was to have a spread in the informants' gender, study programme and school. The informants were four girls and three boys; they study five different programmes in upper secondary at five different schools. Two of the girls are enrolled in the science programme. In this way, the informants are heterogeneous with regard to those three factors.

All students in the study were provided with a video camera and an mp3-player. One student chose to use a digital photo camera instead of a video camera. There was also the opportunity for the students to write ordinary diaries about the subject if they did not want to use the video camera in all situations. The informants were requested to document situations in which they consider science knowledge to be of importance in their daily life outside school. Besides that, all seven teenagers were asked for to comment on their decision about the vaccination against the new influenza. All informants made their diaries during the weeks the vaccination programme was going on. The teenagers made their diaries in 1-3 weeks, and all of them had made their decision about the vaccination when they finished their diaries. They chose to talk about all aspects of the new influenza and vaccination in just one movie clip, which varied a lot in time, between $50 \mathrm{~s}$ and $5 \mathrm{~min}$. After that, the material was transcribed and 1-4 weeks later, semi-structured interviews were conducted by one of the authors. During the interviews, some of the material was discussed with the youngsters, watching a small part of their video diary. The questions were about their vaccination decision and what they thought about their decision afterwards. There were also questions about what they thought about science and their education. The interviews lasted 20-40 min and were recorded and transcribed in Swedish and translated for this article.

Qualitative studies often results in a multitude of data. "The challenge of qualitative analysis lies in making sense of massive amounts of data" (Patton 2002, p. 432). It is necessary to reduce the volume of data in an appropriate way to communicate the essence of what that data reveals. This challenge was to some extent limited in our study. At this stage, all the data could be transcribed and analysed. The other movie clips was mainly about exercise and food and will be analysed later.

\section{Ethical aspects}

The use of a video diary as a data collection tool raises some important ethical aspects. By letting the informant document their daily life, the researcher also runs the risk of getting material that can contain personal information about the informant that requires consideration of how it should be handled. This can for example be information about the family situation, self destructive tendencies and drug habits. The form of the video diary and the fact that the informants have seen documentaries in video diary form may result in some informants exposing themselves very much. The special situation of looking into an individual's life differs from, for example, an interview situation where that type of information can be handled immediately. With a video diary, the researcher is more dependent on the informants' choices even if instructions on what to document are given. In this study, permission from the parents was collected from those students who were under 18 years old. The research followed the ethical guidelines outlined by the National Research Council (CODEX 2010). The interviews were closed with a short briefing where the teenagers were asked if they wanted to say anything more or needed help with anything mentioned in the diary. In the excerpts, the students' identities are kept confidential. 


\section{Analysis}

The video diary and the interviews were analysed in similar way, even if the video diary data was analysed to a certain extent before the interview. In the beginning of the analysis the material was read carefully several times, looking for words that expressed justifications and other expressions about the influenza and the vaccination. These words and expressions were then brought together in themes, guided by the earlier-cited definition given by Potter and Wetherell of interpretative repertoires; "used systems of terms used for characterizing and evaluating actions, events and other phenomena" (1987, p. 149), which sometimes were more explicitly expressed by the teenagers compared to "figures of speech." For example, if words like "uncertainty," "luck" and "never tested" were found in the description, it was categorised as a repertoire about risk, because the teenagers evaluated actions, events and other phenomena with focus on different aspects of risk. In the same way, important expressions or nouns were further categorised. Two more repertoires as well as risk were categorised; solidarity and knowledge. Statements about not only thinking of oneself were categorised in the solidarity repertoire. This includes both relatives and unknown people. In the repertoire of knowledge are gathered statements where knowledge is emphasized. This can be both some demonstrated knowledge or the asking for more knowledge. This first main type of interpretative repertoire including risk, solidarity and knowledge is labelled experienced emphases. Experienced emphases cover much of the action, events and other phenomena that are mentioned in Potter and Weterell's (1987) definition of an interpretative repertoire. The teenagers express how they have acted and why. But there was also need for an analysis of what references the informants made to the actors involved. For that reason, a second major type of interpretative repertoires was created. The second type focuses instead on different types of actors and is labelled important actors. In this second category, the reference to different actors gives origin to the different repertoires, these repertoires are more directly mentioned and thereby rather easy to categorise compared to experienced emphases.

If any relative or friend was mentioned in the reasoning about the influenza and the vaccination, the repertoire was called family and friends. When the teenagers mention anything from the media debate that was going on during the influenza period, the repertoire was labelled media. This can be from television, radio, newspapers and Internet. We were also interested on focusing in what ways school and science education were repertoires used by the teenagers. Since this was the case, school has been categorised into its own repertoire even if the video diaries contained only a single statement about school in connection to the new influenza. Finally, statements made with reference to governments, and also to an anonymous "they" or "it" was still left in the material. These references have been categorised as a society repertoire, even if it is sometimes difficult to identify who they or it are. In this way this major type consists of interpretative repertoires; family and friends, media, school and society.

These different repertoires, both within one main type and between the two different main types, are closely linked together, where reasoning starts in one of them and often ends in another, and they are also sometimes hard to differentiate from each other. The diary often starts in one interpretative repertoire and then goes further to another, searching for arguments. There is also an overlap between the two categories. For example, if a teenager talks about how they have talked a lot about risks in her family but they have decided to have the vaccination; this statement is categorised in both the experienced emphases- and the important actors-repertoire. But this overlap is not seen as a problem as it is not the aim to count how many times the different repertoires are used. 
There is often a high degree of inter-textuality where different texts about the influenza and the vaccination are heard; it is often not possible even to see the origin of the statements. But the emphasis of what matters is different, both between the informants and in different parts of the diary or interview of the same teenager. The different repertoires are reported under different headings even if it is almost impossible to talk about one of them without mentioning one of the others.

Discourse psychology differs from content analysis. In discourse psychology the individual's use of different discourses in the society is investigated. Discourse psychology also differs from a content analysis in its aim, which in discourse psychology is to investigate how people use these different discourses to present themselves. The focus is on how they use language (Potter and Wetherell 1987).

Summary of categorised interpretative repertoires

Main types of interpretative repertoires

Experienced emphases

Important actors
Sub-types of interpretative repertoires

Risk, solidarity, knowledge

Family and friends, media, school, society

After this first analysis where the use of different interpretative repertoires was categorised, we were interested in how the students construct their selves inside a sociocultural context. We wanted to see how their decision-making on the new influenza and vaccination could be understood in relation to the students' self construction in a specific social context. In this second step of the analysis we followed each student in both the video diary and the interview with the aim of seeing how they used the different repertoires to present themselves as informed and responsible citizens.

However, some important conclusions about the difficulties in this study must also be noted. The format of a video diary does not invite deep science content reasoning. Video diaries are not normally adequate in covering investigation into a definition of scientific literacy in which knowledge of science concepts is requested (Driver et al. 1996). Instead, a definition where use and participation is emphasized is more appropriate. For instance is Douglas Roberts' (2007) vision 2 of scientific literacy is more suitable to investigate using video diaries. This is in line with Wolff-Michael Roth and Stuart Lee's (2004) urgent request for the rethinking of scientific literacy in terms of participating in society and Charis Brown's (2010) emphasis on democratic aspects in research. In this way, the video diaries also can be used in a feed-back process as proposed by Quadri and Bullen (2007).

\section{Results}

Experienced emphases

In the examples of the first main type of interpretative repertoires (IR), the experienced emphases are risk, knowledge, and solidarity.

\section{Risk}

This risk repertoire dominates the material and has many different expressions. The risk repertoire becomes a reason irrespective of what decision is made about having the vaccination or not. It is used both to defend a decision to vaccinate and a decision not 
to. If the decision is made not to have the injection, resources that refer to the uncertainty of the knowledge about the vaccine result in a decision where the risks of having the vaccination and thereby the risk of some side effects dominate. In excerpt 1 , Amanda chooses to not have the vaccination and her mainly used interpretative repertoire is risk.

\section{Excerpt 1 (video diary)}

Amanda: I chose not to, not have ehm the shot against the swine flu. Because you don't know what will happen. You read and hear in the news that people have fallen into a coma, ended up in wheel chairs not able to move anymore. // But I don't think anything will happen and if I get swine flu I will survive.

In this way Amanda weighs the risks for and against and expresses her conclusion that there is a higher risk having the injection than not having it. Amanda thinks that a vaccination is connected with more risk than catching influenza. Amanda refers to the flow of media reports, for instance in newspapers during the autumn of 2009, when more or less trustworthy stories about the vaccination were told. Amanda's description of the risks demonstrates a fear of the risks, for instance fall into a coma, end up in wheel chairs. The inter-textuality with reference to media is obvious and this type of reference is common in the material but is handled very differently by different students. Excerpt 1 is also an example of figure of speech (Potter and Wetherell 1987). In excerpt 1, Amanda tells her story in a very dramatic way. This breaking off or pausing speech for dramatic or emotional effect, was common in Amanda's diary.

In the interview that was made after the video diary, Amanda also declares and confirms her choice even if her classmates that had the injection did not get any serious side effects.

\section{Excerpt 2 (interview)}

Amanda: They (those who had the vaccination) were lucky that they did not get anything serious. And if I had the injection, maybe something would have happened, but you never know. I did not dare to take the risk.

Amanda uses the risk repertoire here in the same way, even after a couple of weeks. The lack of serious side effects among classmates that had the vaccination is not seen as an important factor, thus using the risk repertoire in another way. Instead, Amanda talks about not taking the risk and also about luck and destiny. Amanda demonstrates the construction of a view where it is important to avoid risks and where destiny and luck are of great importance.

The large numbers of reports about side effects, and therefore risks, which Amanda uses as resources, are often discussed both in the diaries and in the interviews. But even if the reference to reported risks and side effects are the same, they are used in totally different ways by some students. For example by Anders (excerpt 3), commenting on a You Tubeclip where a girl walks backwards.

\section{Excerpt 3 (interview)}

Anders: Everybody talked about it. There was a guy that pretended that he did it too.

He said, oh no, no and started to walk backwards.

But Anders' story is told with laughter and it is obvious that Anders has not taken the backwards-walking-clip seriously, despite this story and others about people that have fainted during the vaccination at Anders' school. Anders constructs a totally different view of the risks compared to Amanda, even if they both talk about reported side effects of the vaccination. This is also the view of Sandra, one of the girls from the science programme 
who says that "it is just ridiculous that people believe that you would start walking backwards and die, bla, bla." Both Anders and Sandra are aware of the stories about unexpected side effects, but they are not of great concern when constructing their view of the decision. Another example where the risk repertoire ends in a decision to have the vaccination is David. He has also debated with himself and with his mother, resulting in having the vaccination. He states that the positive effects are in favour and that "put safety first." But to put safety first has a different meaning for David compared with Amanda. Both Anders' no, no and Sandra's bla, bla are examples of figures of speech used by the teenagers in this interpretative repertoire.

In the risk repertoire references are often made to the impact of others in decisionmaking about the vaccination. Different types of media seem to play an important part in some of them. It is not so common that the students justify their decision with references to the risk of becoming very ill with the disease. The risk repertoire is closely connected to the next interpretative repertoire; knowledge.

\section{Knowledge}

When the students talk about risks, they are sometimes reasoning about scientific and secure knowledge of swine flu and the vaccination. This debate on what was true of the vaccination and how these facts were proven was very prevalent for a period of several months. This debate was carried out not only in major newspapers and television news, but also in the schoolyard and in social media, like Facebook. When the data involve statements about how you know something or about science-for example, by testing vaccine- the texts have been labelled "knowledge," which gives this knowledge a very broad repertoire. But this is more the use of a knowledge repertoire than a demonstration of using one's own scientific knowledge in this repertoire, even if there are some examples of students that use knowledge about immunology in decision-making. It is also the case in this interpretative repertoire that the vaccination is more discussed than the disease itself.

Both in the video diary and in the interview, Jakob (excerpt 4) expresses certain scepticism about society's knowledge about the vaccine. He is concerned about the tests of the vaccine and what has been proven. Helena (excerpt 5) also expresses doubt about the knowledge about the vaccine.

Excerpt 4 (interview)

Jakob: Of course, you don't know what can happen but if it is not sort of scientifically (2.2) proved that it really does as it was written about, then it's a hard decision but in the end I had it anyway.

Excerpt 5 (interview)

Helena: Well, you couldn't know, the vaccine, you didn't know if it worked or not, it had never been tested, we were guinea pigs.

By mentioning scientifically proved Jakob adds another level to the discussion: not only risk but the importance of knowledge about the vaccine. Jakob emphasizes this by using the expression really does, which can be interpreted as Jakob showing certain scepticism about how public information about the vaccination was drafted. In a similar way, Helena refers to the scientific process (or lack of it) when she uses the metaphor herself as a guinea pig, ready to expose herself to the vaccination. The statements from Jakob and Helena demonstrate that they see scientific knowledge about the vaccine and its effects as insecure and not tested thoroughly enough. This question was also frequently debated in the media and different vaccines were used in different countries. But despite the desire for more 
testing and knowledge about the vaccine, both Jakob and Helena got the vaccination, showing that even if they not are satisfied with the available scientific facts about the vaccine, they are ready to test it for themselves.

In the same way as with risks, Amanda uses the same reference but makes a different decision. Amanda also refers to the lack of scientific proof and uses this to justify her choice to not to have the vaccination.

Excerpt 6 (video diary)

Amanda: Plus that I don't think that they have done enough research on the injection.

It's only just been developed. They don't know what can happen, like side effects and so on. So I don't know, but I don't trust it at all, at all.

Amanda's reasoning is reminiscent of the resources used in the risk repertoire. Amanda expresses the same principle of being careful; she is not ready to test it before she is convinced that it is safe. She emphasizes this with the repetition of at all. The reference to research causes the justification to be classified in the knowledge repertoire, even if the reasoning also consists of risk-safety reasoning.

Excerpt 7 (diary)

Sandra: If people had thought like this about all vaccines, we would still have all the old diseases like rubella etc. Maybe it is wrong to say it, but honestly, it's only ignorant people who choose to not get vaccinated here in Sweden.

Sandra, who attends the science programme in upper secondary school, reasons in another way than Amanda. She thinks that the long experience of earlier vaccination programmes demonstrates the importance of vaccinations and she trusts the scientific community and its knowledge about the issue. She expresses strong trust in science and in scientific knowledge: knowledge is very important and individuals that do not have the vaccination are ignorant.

\section{Solidarity}

Alongside the risk repertoire, the solidarity repertoire dominates. The fact that the teenagers do not vaccinate themselves for their own sake, but instead to protect others from getting the disease, is very often referred to. They refer to protecting close relatives, and also other people in general. Anders repeats his concern for others several times.

\section{Excerpt 8 (video diary)}

Anders: It's not only not to get swine flu myself, but also maybe protect others. If I, don't know, would be hospitalised or something, and then accidently infect innocent people. But it's maybe mostly because I have cousins that are very young, so if I accidently see them and infect them ...so it was most for the sake of others that I really chose to have the vaccination.

Anders shows his concern for his relatives, saying I have cousins that are very young, so if I accidently see them and infect them. But he also expresses solidarity, saying would be hospitalised or something and then accidently infect innocent people. This way of portraying oneself as loyal may function as a very acceptable explanation in discussions about whether to vaccinate or not and it is an argument that is very hard to contradict.

By comparison, this interpretative repertoire involving solidarity is completely absent in Amanda's diary and interview. Amanda, who was the only one of the students that chose not to have the vaccination, neither in the diary nor in the interview mentions anything 
about concern for others, even if she talks a lot about her family in the rest of the diary. But the construction of a world where it is important to care about others is obvious in many other texts. This solidarity was one of the messages in the media and different types of information from governments during the pandemic. The results could also be discussed from the standpoint of Wildavsky and Dake (1990). Solidarity is connected to egalitarianism and individualism which Wildavsky and Dake demonstrate as important factors in risk perception. The lack of a solidarity repertoire by Amanda, might explain that she see risks differently and chooses to not be vaccinated.

\section{Important actors}

The second main type of interpretative repertoire is labelled important actors. These repertoires focus on what types of different actors in society that are referred to in the diaries or during interviews. The purpose of analysing from this perspective as well is to capture texts that are not already captured in the emphasized experiences and in this way complete the analysis. By approaching the data from two different perspectives, the possibility of understanding how students talk about the new influenza and vaccination increases. But it will also give rise to an overlap in the data analysis as some of the data belongs to both types of interpretative repertoires. This double perspective is chosen despite this.

This second perspective in the analysis is mainly a way of analysing the material from an authoritative perspective because earlier research in science education has demonstrated the importance of authorities in decision making (Kolst $\varnothing$ et al. 2006; Lundström and Jakobsson submitted). But the repertoire is labelled actors instead of authorities because the difficulty in analysing if the actor mentioned also can be seen as an authoritysomeone who has the answers. An actor is regarded as important to the scenario but not always trustworthy.

The four labelled interpretative repertoires connected to actors are family and friends, media, school and society. None of these categories are sharply delineated from each other. The society repertoire encompasses the others and is sometimes vague, but despite that is labelled in its own interpretative repertoire.

\section{Family and friends}

The most common repertoire in this main type is family and friends. The new influenza and the vaccination have been major subjects of discussion in the students' homes. Several of the informants talk about lively discussions in their family. But these discussions have not led to the same decision for the entire family. For example Amanda and her father did not have the vaccination, but her mother and brother did. In Jakob's family there have also been discussions about the vaccination. Jakob (excerpt 9) had the vaccination.

\section{Excerpt 9 (interview)}

Interviewer: What did the rest of your family do? Did everybody in the family have the injection?

Jakob: Not my mother.

Interviewer: Ok, why not?

Jakob: On one hand because she is, I suppose you'd say, critical, in the way I am too. I don't know why I had it. Maybe because I spend a lot of time with my grandmother, and my father has always said that, that it's young people and the elderly that are in 
the danger zone. And that put some group pressure on, in a way, or family pressure. My mother did not have the vaccination because we have a family doctor that told her you don't need the vaccination and so on. So she trusted him. So that's how it went.

Jakob's discussion demonstrates a repertoire in which Jakob has to adopt an opinion that accommodates the divergent views of his family. On one hand, Jakob identifies with his mother, saying she is, I suppose you'd say, critical, in the way I am too. On the other hand, Jakob feels pressure from his father, referring to his father's concern about grandmother and the elderly in the danger zone. This pressure from his father outweighs other concerns and even in the video diary Jakob justifies his decision to be vaccinated by referring to his father's wish in the same way as he does in the interview. Jakob also brings in an important actor with connection to the family-the family doctor. The family doctor seems to be decisive for Jakob's mother's decision but not for the rest of the family. This, despite the doctor's recommendation is contrary to the main message from the governments, governments that Jakob both in the video diary and the interview expresses a critical view about.

As well as the family, friends have also been discussion partners in deciding and evaluating the effects of having the injection or not, and especially in discussing the different side effects. The discussion about the side effects is illustrated in excerpt 3 , an excerpt that illustrates how the students refer to discussion among friends. While in excerpt 3 Anders demonstrates a rather relaxed attitude, Amanda and her friends, were according to Amanda (excerpt 10), really afraid. Amanda talks about this in a dramatic style also in the interview.

\section{Excerpt 10 (interview)}

Amanda: Almost nobody in my class has had the vaccination. They are all afraid of it too.

Interviewer: Ok, you think it was for the same reason that you had, that they thought there would be side effects?

Amanda: Yes, yes! Because everybody talked about it in the classroom. That things had happened and so on.

Both excerpt 3 and 10 demonstrate that discussions that students commonly refer to are often those in which they have discussed different side effects with their friends. They are not to any great degree referring to discussions with friends about swine flu itself. The interpretative repertoire once again focuses on the vaccination and not on the influenza.

\section{Media}

As reported earlier, the media coverage of the pandemic and the vaccination programme was massive. What dominates in this interpretative repertoire is the students' stories of what the vaccination may result in. The types of statements demonstrated in excerpts 1 and 3 and associated results are common in the media repertoire. The statements in excerpt 1 and 3 are made emotionally. These emotions can be both fear (Amanda) and laughter (Anders). The media reports about possible side effects dominate, while the rest of the media reports have not been forceful enough to play an important role in students' available repertoires. None of the students discuss, for example, the number of deaths or the symptoms of the disease. That type of media reporting has not influenced the students' discussions about the new influenza. There is only one example where a student refers to 
the media in another way than connection to side effects. In excerpt 11 Jakob demonstrates an interest in media reports.

Excerpt 11 (video diary)

Jakob: This is very hard, because later, around the $20^{\text {th }}$ of February 2010 I read in the newspaper that all this about the influenza was fake and that it just earned money for the industry producing the vaccine.

In this way, Jakob expresses doubt about how necessary the mass vaccination was, referring to newspapers. The media repertoire seems to a high degree also to be the origin of other repertoires, like the risk repertoire (see excerpt 1 and 3). The previously-mentioned solidarity repertoire was frequently emphasized in the media. However, even if it is used by the informants, they seldom explicitly refer to media in such reasoning like this. It also seems as if the different stages in Ungar's (2008) established genre for how to report on scientific risks are differently interpreted by the different student's, even though the video diaries and interviews were made during a short period. Amanda often refers to the first stage, sounding the alarm, while the other teenagers refer more often to the other stages.

School

One of the purposes in this study was to investigate if the students referred to school and science education as an available repertoire of their new influenza discourse. However, there is only one student that comments about school in the video diary; Anders mentions school briefly as the place for the vaccination. This fact indicates a lack of information or discussion in school, at least in a way that prompts the students to express a "school agenda" in their diaries. But the interviews give a different image of school and the discussions about the vaccination. Interpretative repertoires involving school are common in the interview material because the interviewer asked about activities in school connected to the new influenza and the vaccination. In excerpt 12, Amanda talks about her mentor or teacher responsible for them in a general way, who brought up the discussion about the vaccination when he met the students he is responsible for.

Excerpt 12 (interview)

Amanda: No, our teacher doesn't try to influence us very much, he just tells it how it is

\section{I: Yes}

Amanda: And he thought we should do it. He said that I think that you should have it but I cannot as said, force you.

Amanda is fond of her teacher who she thinks is a good person who only tells the truth; he just tells it how it is. But at the same time while she understands the teacher is trying to demonstrate a neutral view, she also refers to him in the same sentence I think that you should have it and also, but maybe not so obviously, in I cannot force you. These two statements may be interpreted that Amanda also in a way sees him as an authoritative actor, trying to affect the students' choice. This authoritative voice from school is seen also in other interviews.

This "vaccination message" is one of the two themes that can be found in the school repertoire; the other one is the information about hygiene that students see as the major message from school. 


\section{Excerpt 13 (interview)}

I: Was it something you talked about in school? In lessons or so on, with the teacher?

David: Well, it was brought up sometimes in lessons. And then they brought it up in the meeting about washing our hands carefully, properly with soap and so on, after going to the loo. And before we ate and after we had eaten and so on.

David and other students in the study are influenced by this repeated hygiene message; washing our hands carefully, with soap and so on. This message was also dispersed in the media during the pandemic. But the lack of any lessons connected to the disease, immunology, is clear. The students are not in any case talked to in any "ordinary" lessons where the subject is highlighted. The vaccination or hygiene message is delivered by any teacher, not necessarily the science teacher. Often it is students' mentor or a teacher responsible for them in a general way. The teenagers' stories demonstrate that even if the influenza was not discussed in lessons, the school served as a venue for discussions about the disease and vaccination among the teenagers.

\section{Society}

Some of the students reason at a level that is national or abstract. Often the students using this repertoire demonstrate an engagement in understanding why the decision about offering free vaccine has been made. This interpretative repertoire is a mix of different actors, either where it not has been possible in a clear way to define what is meant in a statement about they or when the discussion is on a level above nearby actors, like family or teachers. Jakob reasons about the government's policy to offer free vaccination for all citizens.

\section{Excerpt 14 (video diary)}

Jakob: The vaccination was a flop but at the same the government could not have done anything else. Because if they had not bought in the vaccine then it would have been a disaster for the government. Because everybody had started questioning... no, it was not possible. No, they had to offer a bit of protection for the public.

Jakob, who has earlier demonstrated an interest in social matters, is critical but at the same time understands the reasoning of the government. He emphasizes his opinion by repeating "no" in the last two sentences.

This repertoire is closely connected to the knowledge repertoire, reported in excerpts 4-6. The students mean that society has a great responsibility to test the vaccination to ensure it is alright.

\section{Identity constructions}

The interpretative repertoires reported above are used by the students to justify decisions about the vaccination against the new influenza. Often, several repertoires are used by the students to justify their opinion on the issue. But how do the different interpretative repertoires stand against each other? Are certain repertoires more important for some of the students and how do the students in the study express what is of greatest concern in their decision-making? In order to investigate more deeply an individual's decision-making and the individual's self-presentation in a socio-scientific issue, we also follow three students' argumentation through the video diary and the interviews. Every teenager constructed their own identity. We have chosen Amanda and Sandra because they constructed opposite 
identities. The third student is Jakob, who was chosen because he on several occasions talked about himself as critical, which is of interest for this study.

\section{Amanda}

We have seen examples of Amanda's reasoning in excerpt 1, 2, 6, 10 and 12. Why Amanda's diary and interview are so interesting is primarily because of the reason she decided against the vaccination, but also because of how she talks about her decisionmaking. Amanda uses different repertoires in her video diary. Among the experienced emphases she uses both risk (excerpt 1) and knowledge (excerpt 6). The risk repertoire is important for Amanda, who describes herself as a girl who does not take any risks. The risks of having the vaccination are greater than not having it, Amanda thinks. But equally interesting is the lack of a solidarity repertoire in Amanda's video diary. Even in the interview, despite the interviewer bringing her family into the discussion about the vaccination, she did not mention anything about concern for others in relation to catching influenza. Amanda sees the vaccination as a fateful moment (Giddens 1991) where she hopes she will be lucky, talking about her destiny and showing in this way that she also sees something in this subject that she cannot control.

Amanda's use of the important actors-repertoire strengthens the picture we have of her decision. She refers to media where she has read about various serious side effects. This reasoning takes much more space than establishing the fact that her mother and brother have had the vaccination without getting any serious side effects, something mentioned only very briefly. The school repertoire is not used by Amanda in her video diary. The society repertoire is represented by they in a statement made by Amanda (Excerpt 15). But who they are is not explicit.

\section{Excerpt 15 (video diary)}

Amanda: They do not know what can happen, with side effects and things like that. So I don't know, but I don't trust it at all, at all.

The image Amanda gives of herself is that of a girl who controls her life by being sceptical to what other actors tell her about the vaccination, with the exception of the media. Amanda refers to the media which have told a story about risks and what can happen when you decide to be vaccinated - an image that is consistent with her own about luck and destiny.

\section{Jakob}

Jakob describes himself as an individual who is concerned about social issues. He demonstrates in his video diary a suspicion against the whole vaccination project, referring to newspapers and using the media repertoire diligently. In this way he also demonstrates that he is a citizen that follows media reports but is critical (excerpt 11, 14). He uses the knowledge and risk repertoires only briefly to emphasize society's lack of knowledge about the vaccine. Jakob is one of the informants who reports some types of forced solidarity where he is critical about having the vaccination but mentions a pressure from others that seems to convince him to go ahead with it. Jakob thinks that his father had great influence on his decision. His father's influence is more important than the family doctor's who recommended Jakob's mother not to have the vaccination. In this way, the family and friends repertoire is demonstrated as very important for him, as it is for several students in the study. Jakob does not mention school at all in his video diary. Jakob demonstrates that 
school and science education have not been important actors for him. In the interview Jakob mentions the school's contribution as one teacher brought it up but it was not an indepth lesson, only about how many that had been vaccinated. School and science education has not, according to Jakob, contributed in helping him make an informed decision.

Sandra

Sandra is the student that argues most strongly for the vaccination. She constructs herself as an enlightened girl, supporting the scientific community and its ideas. Both in her diary and the interview she is consistently positive to science, without any doubts. This lack of doubt separates her from the other students who sometimes express doubts about the vaccination or the information about it. Sandra suggests that diseases are more dangerous than vaccinations. She uses the media repertoire only as instances of what is, according to her, stupid examples of what people believe in. Sandra is intolerant towards individuals that choose not to have the vaccination (see excerpt 7). However, these intolerant statements should not be confused with solidarity. Sandra justifies her decision about the vaccination not only using the knowledge repertoire, by demonstrating some knowledge of biology, but also by using the solidarity repertoire. She asserts that for instance elderly individuals are more in danger than younger, and that the implication of this is that younger people have the responsibility to be vaccinated and thus not infect the elderly.

\section{Discussion}

This study differs from many other studies conducted about scientific literacy and decisionmaking because the decision under investigation was made outside school. All the informants had to justify their decision, thus presenting themselves as rational individuals, capable of handling dilemmas. By using discourse psychology and the concept of interpretative repertoire (Potter and Wetherell 1987) we have strived to analyse students' justifications for their decision-for example how they describe themselves shortly after the decision about having the vaccination or not. However, the students' arguments are not regarded as stable, but instead as constructions that might change in another context, under other circumstances, but despite that of interest for science education.

As we have demonstrated was the vaccination decision justified in many different ways by the teenagers. They often used more than one repertoire to justify the decision. As mentioned in the results, the different repertoires were differently emphasized in the teenagers' reasoning. The result demonstrates that the students see the vaccination decision to a high degree as a risk assessment. The concern about risks as discussed by Beck (1999) and Giddens (1991) is very obvious in the study, at an individual level. All individuals in the study use the risk repertoire and try to deal with the issue from their perspective. We can see how the risk repertoire is used by the students, but that the outcome of their reasoning results in different decisions. Often, the risk is connected with the vaccination and not with the disease itself unlike Duggan and Gott's (2002) study where parents emphasized the incidence of the disease. Even if the teenagers in this study are often of age, as teenagers their parents still had a large impact on their decision. The conclusion is that parents' influence over children's vaccinations and importance of personal experiences reported by Poltorak et al. (2005) and Ideland (2007) also seems to be valid for adolescents. But the fact that six of the seven students in the study vaccinated themselves indicates that the consideration of the effects of the disease has been important to the 
students. When the risks are discussed, side effects seem very important. For example, both Amanda and Jakob talk about the risks of side effects and the lack of testing as discussed in the media, but they value the information differently and come to different decisions. This is not surprising; the likelihood of side effects are difficult for patients and consumers (Peters et al. 2007). In the case with the new influenza vaccination this discussion about side effects took place amongst scientists and in newspapers more than a year after the vaccination campaign. Amanda says she is really concerned about risks, seeing the vaccination as a fateful moment (Giddens 1991) that may have very large consequences, while Sandra, Jakob-and also for example Anders-have a more relaxed, but concerned view. Why this difference? Jakob speaks of discussions about the new influenza and vaccination using the family and friends repertoire. In Jakob's family, they came to different decisions about the vaccination. This is also the case in Amanda's family, but the sort of family discussion reported by Jakob is not reported by Amanda. Amanda does not use the solidarity or family and friends repertoires, two repertoires that are closely connected. It cannot be said that Jakob has made the right decision and Amanda the wrong one, but discussion with the family seems to be of importance for Jakob and Anders but not for Amanda in decision-making about the vaccination. The family and friends repertoire seems to contrast some of the most spectacular media reports. Several of the students think about the media reports and their conclusions about the reports indicate that they have a critical view of media reporting but find them hard to evaluate, as reported by Korpan et al. (1997). The media repertoire seems available to use by all students, but it is also the repertoire that is used in very different ways and not always explicitly expressed. Anders uses it as an anecdote among class mates, Sandra as not something to trust in, Jakob as source for discussion about social issues and Amanda as a trustworthy information source. These diverging uses of this repertoire demonstrate its importance.

The school repertoire is represented through two main messages; the students' reception of the teachers' message about having the vaccination and the hygienic message, where the importance of washing hands is emphasized. The influenza and vaccination have not been in focus in ordinary lessons, led by a science teacher: instead the two received messages come from any subject teacher. The school repertoire is not expressed in the video diaries, only in the interviews, indicating that school and science education are not important actors for the decision.

\section{Implications}

How can science education take advantage of these results? The importance of solidarity and family and friends when making the vaccination decision is obvious. We are arguing for a science education that has its point of departure in questions that impact the student's life or the life of his or hers relatives. By starting close to the student's daily life when working with socio-scientific issues, it is possible to understand what arguments the student meets outside school. Looking for and discussing Gidden's (1991) fateful moments may be one way to begin. This conclusion supports Ratcliffe and Grace (2003) who assert that on a personal level values and beliefs are of great importance in decision-making. When this is the case, the arguments from family and friends are central and must be discussed by school and science education. However, we think that science education must find a way to reason from this personal level but with the help of scientific reasoning. We also emphasize the importance of working with media reports and media critics in socioscientific issues as media reports are cited diligently. As demonstrated by, for example, Kolstø (2006), Korpan et al. (1997) and this study, media reports can be complex and 
interpreted in different ways. The result in our study indicates the need to use media reports in dealing with scientific literacy, but also the need to analyse media in general in a critical way, discussing the presented facts and conclusions. For example, Anders and Amanda interpret the media reports in totally different ways, despite the fact that they refer to the same reports. This result is in line with the suggestions from McClune and Jarman (2010) who suggests that a "media awareness" must be considered in science education in the future. To be scientific literate will include being media literate, to understand how media functions.

Christensen (2009) says that an individual's lack of personal control in risk situations and poor confidence in participating in decision-making can be explained by that individual's schooling. We agree with her suggestions about a science education where risk analysis and the sometimes uncertain results of scientific research are discussed. This will, according to Christensen (2009) lead to challenges for science education, such as presenting science in a social context and dealing with uncertainties in science. Edgar Jenkins (1999) also argues for a science education where risk assessment is one important part of the activities and means that risk is one of the situations where a citizen will be confronted with science.

As in studies by Ekborg (2008), Kolstø (2006), other important actors/authorities are shown to be important to decision-making. In this study, actors such as family and friends, teachers, governments, scientists and the media are mentioned as carriers of information that the students must deal with. Which important actor repertoire is possible to use in making the decision differs between the informants, but raises the question of how these important actors in some way can be a part of the agenda in science education? We mean that science education must be able to help students evaluating actors involved in a socioscientific issue, to become citizens that use a scientific repertoire as well as other repertoires.

One of the purposes with this study was to investigate if the students show that school and science education are useful/possible repertoires in the new influenza discourse, amongst others. There is only one student in the study, Sandra, who reasons with clear use of scientific knowledge and present herself with an identity connected to the scientific community (Brickhouse 2001). She refers to the history of medicine and how vaccinations have exterminated some diseases that some 100 years ago killed many in pandemics. The other students do not explicitly demonstrate deep knowledge of immunology in the diaries or interviews, even if they are enrolled in the same programme in upper secondary school. However, the solidarity with others, not wanting to infect others, may demonstrate knowledge of how to avoid passing on the new influenza. The use of scientific concepts is not common, but this may be explained by the fact that the video diary format does not support a scientific vocabulary but encourages instead an everyday language. The difficulty of using scientific concepts is not surprising and this agrees with other studies about using scientific concepts in other contexts (Aikenhead 2006). The construction of the different identities did not in our analyses demand any deeper scientific reasoning. Instead the talk about science has been of interest even if it mainly has been talk about what the scientists really know about the vaccination. In this way, everyday language has not been an obstacle in our study. However, seen from another perspective the lack of being able to use scientific knowledge in different contexts is a problem for science education (Roberts 2007). The results cannot be explained by study programme. The other girl enrolled in the science programme, Cornelia, constructed a completely different identity compared to Sandra. Cornelia did not express any scientific knowledge as the basis for her decision. The teenagers did not clearly demonstrate that they control the scientific knowledge that was 
appropriate when making a decision about the vaccination. The results support Jenkins (2006) who suggests that the need for science knowledge as a part of an active citizenship has been discussed for many years, to not avail. The scientific knowledge was not explicitly investigated and should not be over emphasized but the results questions the results obtained by Ryder (2001) about being able to learn appropriate science in situations that demands it. Jenkins (2006) emphasizes that this view of science education as a part of an active citizenship requires a wider knowledge base than what is provided by traditionally school disciplines in biology, chemistry and physics — something the results in this thesis support. The vaccination decision was an example where scientific knowledge could support the decision, but for example Amanda, Sandra and another girl named Helena, did not demonstrate any knowledge connected to the issue, neither in the video diaries, nor in the interview. Despite that, six of the teenagers made the decision that was proposed by most of the scientists involved in Swedish health care.

The school repertoire was, as reported, uncommon in the material. One explanation for this can be the design of the upper secondary school where different courses are studied over 3 years. If the curricula of the courses do not include this issue during the period of the vaccination, the school is not able to treat the problem from the science teacher's perspective, but instead has to deal with the issue in another way. These organisational and further problems of dealing with current topics may be investigated in further studies.

This study does not claim that the interpretative repertoires found in this study are the only ones possible in a study on a socio-scientific issue concerning health. The students did not talk about the disease and its consequences as if the world would have stopped-something that might have been the case if the study had been made in another country, where the new influenza claimed more victims. But we think this study has opened up the possibility for more studies about focusing on different interpretative repertoires, not just in science education, but also in daily life outside school. We also think that the use of video diaries may be a starting point for investigating scientific literacy "in the wild" (van Eijck and Roth 2010) even if a request from a researcher cannot be regarded as completely "in the wild."

The study raised important methodological questions. The video diary format may attract certain types of informants who enjoy its expository nature. The teenagers in our study were different personalities, but all had a willingness to expose parts of their life to a researcher. We see the video diaries as an appropriate tool when studying scientific literacy and identity construction (Sadler 2009). The participatory possibilities of video diaries can be used to investigate how decision-making and reasoning can be shared with others in the construction of a discursive identity (Brown et al. 2005). However, we agree with Gibson (2005) and Pink (2001) who argue that the informants present themselves in accordance with what is expected of them, but also how they want to be perceived in relation to those expectations. These two views can sometimes be in line with each other, sometimes in conflict. The connection to personal health made our video diaries even more problematic and raised ethical considerations of how to act and what reactions this type of data collection provokes. These methodological and ethical considerations will be more discussed in a separate article (Lundström et al. in progress).

\section{References}

Aikenhead, G. S. (2006). Science education for everyday life. Evidence-based practice. New York: Teachers College Press.

Beck, U. (1992). Risk society towards a new modernity. London: Sage Publications. 
Beck, U. (1999). World risk society. Oxford: Blackwell Publishers Ltd.

Brickhouse, N. W. (2001). Embodying science: A feminist perspective on learning. Journal of Research in Science Teaching, 38, 282-295.

Brown, C. (2010). Pacific consumer acculturation in New Zealand: Understanding the dynamics of consumption using video diaries. Doctoral thesis at the University of Waikato.

Brown, B. A., Reveles, J. M., \& Kelly, G. J. (2005). Scientific literacy and discursive identity: A theoretical framework for understanding science learning. Science Education, 89, 778-802.

Buchwald, D., Schantz-Laursen, B., \& Delmar, C. (2009). Video diary data collection in research with children: An alternative method. International Journal of Qualitative Methods, 8(1), 12-20.

Burchell, K., Franklin, S., \& Holden, K. (2009). Public culture as professional science. London: BIOS, London School of Economics and Political Science.

Chang, S.-N., \& Chiu, M.-H. (2008). Lakatos' scientific research programmes as a framework for analysing informal argumentation about socio-scientific issues. International Journal of Science Education, 30, 1753-1773.

Christensen, C. K. (2009). Risk and school science education. Studies in Science Education, 45, $205-223$.

CODEX. (2010). Rules and guidelines for research. The Swedish Research Council and Uppsala University. Retrieved December 26, 2010, from http://www.codex.vr.se.

Cotton, D. R. E., Stokes, A., \& Cotton, P. (2010). Using observational methods to research the student experience. Journal of Geography in Higher Education, 34, 463-473.

Driver, R., Leach, J., Millar, R., \& Scott, P. (1996). Young people's images of science. Buckingham: Open University Press.

Duggan, S., \& Gott, R. (2002). What sort of science education do we really need? International Journal of Science Education, 24, 661-679.

Ekborg, M. (2008). Opinion building on a socio-scientific issue: The case of genetically modified plants. Journal of Biology Education, 42(2), 60-65.

Fairclough, N. (1992). Discourse and social change. Malden: Blackwell Publishers Inc.

Gibson, B. E. (2005). Co-producing video diaries: The presence of the "absent" researcher. International Journal of Qualitative Methods, 4(4), 1-9.

Giddens, A. (1991). Modernity and self-identity-self and society in the late modern age. Cambridge: Polity Press.

Holliday, R. (2004). Filming "The Closet": The role of video diaries in researching sexualities. American Behavioral Scientist, 47, 1597-1616.

Ideland, M. (2007). Sick children. How medial and personal experiences are woven together. Ethnologia Scandinavica, 37, 63-71.

Irwin, A., \& Wynne, B. (1996). Misunderstanding science: The public reconstructions of science and technology. Cambridge: Cambridge University Press.

Jarman, R., \& McClune, B. (2010). Developing students' ability to engage critically with science in the news: Identifying elements of the 'media awareness' dimension. Curriculum Journal, 21(1), 47-64.

Jenkins, E. W. (1999). School science, citizenship and the public understanding of science. International Journal of Science Education, 21, 703-710.

Jenkins, E. W. (2006). School science and citizenship: Whose science and whose citizenship? The Curriculum Journal, 17(3), 197-211.

Kolstø, S. D. (2001). 'To trust or not to trust,...'-pupils' ways of judging information encountered in a socio-scientific issue. International Journal of Science Education, 23, 877-901.

Kolst $\varnothing$, S. D. (2006). Patterns in students' argumentation confronted with a risk-focused socio-scientific issue. International Journal of Science Education, 28, 1689-1716.

Kolstø, S. D., Bungum, B., Arnesen, E., Isnes, A., Kristensen, T., Mathiassen, K., et al. (2006). Science students' critical examination of scientific information related to socioscientific issues. Science Education, 90, 632-655.

Korpan, C. A., Bisanz, G. L., Bisanz, J., \& Henderson, J. M. (1997). Assessing literacy in science evaluation of scientific news briefs. Science Education, 81, 515-532.

Lave, J., \& Wenger, E. (1991). Situated learning. Legitimate peripheral participation. Cambridge: University of Cambridge Press.

Lemke, J. L. (2001). Articulating communities. Socio-cultural perspectives on science education. Journal of Research in Science Teaching, 38(3), 296-316.

León, B. (2008). Science related information in European television: A study of prime-time news. Public Understanding of Science, 17, 443-460.

Lundström, M., Ekborg, M., \& Ideland, M. (in progress). Using video diaries in studies about scientific literacy.

Lundström, M., \& Jakobsson, A. (submitted). Students perceptions about scientific trustworthiness. 
McClune, B., \& Jarman, R. (2010). Critical reading of science-based news reports: Establishing a knowledge, skills and attitudes framework. International Journal of Science Education, 32(6), 727-752.

Nerlich, B., \& Halliday, C. (2007). Avian flu: The creation of expectations in the interplay between science and the media. Sociology of Health \& Illness, 29(1), 46-65.

Norris, S. P., Phillips, L. M., \& Korpan, C. A. (2003). University students' interpretation of media reports of science and its relationship to background knowledge, interest, and reading difficulty. Public Understanding of Science, 12, 123-145.

Noyes, A. (2004). Video diary: A method for exploring learning dispositions. Cambridge Journal of Education, 3(2), 193-209.

OECD. (2003). Assessment framework - mathematics, reading, science and problem solving knowledge and skills. Retrieved November 10, 2005 from http://www-skolverket.se/sb/d/254/a/1121.

OECD. (2007). PISA 2006, science competencies for tomorrow's world. Retrieved January 10, 2008 from http://www.pisa.oecd.org/document/.

Osborne, J., \& Dillon, J. (2008). Science education in Europe: Critical reflections. A report to the Nuffield Foundation.

Patton, M. Q. (2002). Qualitative research \& evaluation methods. Thousand Oaks: Sage Publications.

Peters, E., Hibbard, J., Slovic, P., \& Dieckmann, N. (2007). Numeracy skill and the communication, comprehension, and use of risk-benefit information. Health Affairs, 26(3), 741-748.

Pink, S. (2001). Doing visual ethnography. London: Sage Publications.

Poltorak, M., Leach, M., Fairhead, J., \& Cassell, J. (2005). "MMR talk" and vaccination choices: An ethnographic study in Brighton. Social Science and Medicine, 61, 709-719.

Potter, J., \& Wetherell, M. (1987). Discourse and social psychology-beyond attitudes and behavior. London: Sage Publications Ltd.

Powell, M., Dunwoody, S., Griffin, R., \& Neuwirth, K. (2007). Exploring lay uncertainty about an environmental health risk. Public Understanding of Science, 16, 323-343.

Quadri, N., \& Bullen, P. (2007). Exploring students' views with video diaries. SOLSTICE 2007 conference. Edge Hill University.

Ratcliffe, M., \& Grace, M. (2003). Science education for citizenship. Teaching socio-scientific issues. Maidenhead: Open University Press.

Roberts, D. A. (2007). Scientific literacy/science literacy. In S. K. Abell \& N. G. Lederman (Eds.), Handbook of research on science education. Mahwah, New Jersey: Lawrence Erlbaum Associates, Publishers.

Roth, W.-M. (2008). The nature of scientific conceptions: A discursive psychological perspective. Educational Research Review, 3, 30-50.

Roth, W.-M., \& Lee, S. L. (2004). Science education as/for participation in the community. Science Education, 88(2), 263-291.

Ryder, J. (2001). Identifying science understanding for functional literacy. Studies in Science Education, 36, $1-42$.

Sadler, T. (2009). Situated learning in science education: Socio-scientific issues as contexts for practice. Studies in Science Education, 45, 1-42.

Sadler, T. D., \& Zeidler, D. L. (2005). Patterns of informal reasoning in the context of socio-scientific decision-making. Journal of Research in Science Teaching, 42(1), 112-138.

Shafir, E., Simonson, I., \& Tversky, A. (1993). Reason-based choice. Cognition, 49(1-2), 11-36.

Swedish Institute for Infectious Disease Control. (2010). Retrieved June 09, 2010 from http://www. smittskyddsinstitutet.se Smittskyddsinstitutets hemsida.

Toulmin, S. E. (2003). Uses of argument. Cambridge: Cambridge University Press.

Tytler, R., Duggan, S., \& Gott, R. (2001). Dimensions of evidence, the public understanding of science and science education. International Journal of Science Education, 23(8), 815-832.

Ungar, S. (2008). Global bird flu communication. Hot crisis and media reassurance. Science Communication, 29, 472-497.

Van Eijck, M., \& Roth, W.-M. (2010). Theorizing scientific literacy in the wild. Educational Research Review, 5, 184-194.

Wenger, E. (2008). Community of practice. Cambridge: Cambridge University Press.

Wetherell, M., \& Potter, J. (1992). Mapping the language of racism. Discourse and the legitimation of exploitation. Hempel Hempstead: Harvester Wheatsheaf.

Wildavsky, A., \& Dake, K. (1990). Theories of risk perception: Who fears what and why? Daedalus, 119(4), 41-60.

Winther Jørgensen, M., \& Phillips, L. (2000). Diskursanalys som teori och metod. [Discourse analysis as theory and method] Lund: Studentlitteratur.

Wynne, B. (1991). Knowledges in context. Science, Technology and Human Values, 16(1), 111-121. 
You Tube. (2010). Retrieved September 16, 2010 from http://www.youtube.com/watch?v=oGT0r-udstQ\& feature=related.

\section{Author Biographies}

Mats Lundström has a PhD in Education at Malmö University. His research interests are science education and teenagers' opinions about trustworthiness and their use of scientific knowledge. The title of his doctoral thesis is: Decision-making in health issues: Teenagers' use of science and other discourses. Mats Lundström works at the Faculty of learning and society at Malmö University. Before this, he worked as a science teacher in lower secondary school.

Margareta Ekborg is professor in science education at Malmö University, Sweden. Her research interest is socio-scientific issues and education for sustainable development with focus on use of scientific knowledge.

Malin Ideland is associate professor in European ethnology and senior lecturer in Educational Sciences at Malmö University, Sweden. Her main research areas are (1) identity construction in science education and education for sustainable development and (2) cultural perspectives on biotechnologies like gene technology, vaccinations and stem cell research. 